RECORD OF TECHNICAL CHANGE

Technical Change No.

2

Page 1 of 4

Project/Job No. 799417.00030010

Date $11 / 19 / 99$

Project/Job Name CAU 143: R-MAD/E-MAD Contaminated Waste Sites, Nevada Test Site, Nevada

The following technical changes (including justification) are requested by:

Jeff Johnson

(Name)
Task Manager

(Title)

\title{
Technical Change:
}

The proposed CPT push locations at CWD $\$ 2$ E-MAD Trench have been changed. Replace Figure 4-3 with the attached revised Figure 4-3.

\section{Justification:}

The disposal of waste at the E-MAD Trench is limited to the portion of the trench between the large mound of soil and the open portion of the trench. The biased locations targeted for the investigation are shown on the revised Figure 4-3. The adequacy of this approach is supported by the following rationale:

- Disposal activities are limited to solid waste.

- It is assumed that the sidewall slope within the covered area is the same as in the open trench. This would result in any waste that was placed in the trench falling to the center of the trench. Three pushes are proposed along the center line of the trench.

- Two additional pushes are proposed at off-center locations to check sidewall conditions.

\section{Technical Change:}

Section 4.1.2, "Cone Penetrometer Testing," Page 31, Second Paragraph. Change to read:

The CPT will be used to define subsurface conditions, gather field analytical data, and subsequently substantiate or refute the conceptual model established during the DQO process. The CPT pushes will be advanced within or adjacent to areas where wastes are believed to have been disposed. Proposed initial primary and lateral push locations are identified in Figures 4-2 and 4-3. The exact locations will be determined upon initiation of field activities. Generally, CPT pushes will be advanced until the bottom of the feature under investigation is identified or until refusal. Roto-Sonic drilling will be used to verify the amount of cover material at waste disposal locations, further identify the bottom of the feature, and collect environmental and geotechnical samples at selected locations. The Roto-Sonic boreholes will be completed a minimum of 10 feet into native material at each location.

Page 32, First Paragraph - delete first sentence. 


\section{Justification:}

The characterization locations for CAU 143 were selected as biased locations based on process knowledge and geophysical data as part of the DQO and CAIP approval process. The use of CPT for the characterization of these previously selected locations has resulted in the targeting of specific locations where COPCs are most likely to be present for confirmation and sampling. Locations yielding background field analytical results will also be selected for confirmation and sampling.

The CPT was able to collect data identifying location with gamma and VOC concentrations greater than background. The CPT was not able to continue an additional 10 feet into native material as required by the CAIP. The field analytical results will be verified and the CAIP depth requirement will be satisfied at selected locations by using Roto-Sonic drilling.

The use of biased Roto-Sonic sampling locations will provide representative results for determining the nature and extent of $\mathrm{COCs}$, migration, and geotechnical results for the site. The proposed number of locations, approximately 15 including step outs, in lieu of the 40 pushes originally planned, will be drilled to satisfy the CAIP requirement of completing investigation pushes or boreholes 10 feet into native material. However, the proposed number of Roto-Sonic sampling locations is more than the originally proposed eight locations to be sampled for confirmation. The adequacy of this approach is supported by the following rationale:

- An estimated $100 \mathrm{CPT}$ pushes have been completed at the site. This includes primary pushes, offset pushes, and step-out pushes at background locations, R-MAD East, R-MAD West, Bottle Pit, and E-MAD. This is more than twice the number of pushes proposed in the CAIP. This is additional information that was not previously available that can be used to refine and focus the final sampling effort. This phased characterization/sampling approach was presented and approved in the CAIP.

- The CAIP identified 12 locations in the immediate vicinity of R-MAD West Trenches for characterization. The specific locations were investigated and an additional 21 pushes were completed for a total of 33 pushes including offsets and step outs. Field analytical results indicated gamma and VOCs greater than background within this area. At the R-MAD West Trenches the vertical and lateral extent of contamination will be verified with four primary and a minimum of three step-out boreholes. The Roto-Sonic boreholes will be completed a minimum of 10 feet below the identified bottom of the trenches.

- The CAIP identified eight locations in the immediate vicinity of R-MAD East Trestle for characterization. The specific locations were investigated and an additional 16 pushes were completed for a total of 24 pushes including offsets and step outs. Field analytical results indicated gamma and VOCs greater than background within this area. The vertical and lateral extent of contamination will be verified with two primary and a minimum of two step-out boreholes. A minimum of one borehole will be completed to a depth of 50 feet to determine the nature or presence of the possible anomaly identified during the geophysical investigation under the trestle.

- The CAIP identified five locations on the TNT Mound for characterization. Field analytical results indicated VOCs greater than background at two locations within the mound. Gamma was not greater than background at any location within the mound. Roto-Sonic drilling will be used at the TNT Mound at one location for verification of the CPT results and to collect a sample from under the mound to satisfy the CAIP requirement. 
- The CAIP identified 10 locations in other locations in R-MAD East for characterization. These locations were anomalies identified during the geophysics investigation or based on process knowledge. Eight specific locations were investigated and an additional 10 pushes were completed for a total of 20 pushes including offsets and step outs. The two locations that were not investigated were on the eastern cooling berm and were not accessible to the CPT rig. Field analytical results indicated gamma and VOCs greater than background at different locations within this area. Within the R-MAD East area the vertical and lateral extent of contamination will be verified with three primary boreholes. The Roto-Sonic boreholes will be completed a minimum of 10 feet into native material.

- The number of CPT pushes used to characterize the E-MAD trench (5 pushes) specified in the CAIP will be satisfied. It is assumed that the depth requirements can be satisfied at the E-MAD Trench and the required samples can be collected using CPT. Roto-Sonic drilling/sampling will be used at the E-MAD Trench, if necessary.

The project time will be (Increased)(Decreased)(Unchanged) by approximately $\ldots$

Applicable Project-Specific Document(s):

Corrective Action Investigation Plan for Corrective Action Unit 143: Area 25 Contaminated Waste Dumps,

Nevada Test Site, Nevada, Rev. 1, June 1999; DOE/NV--506

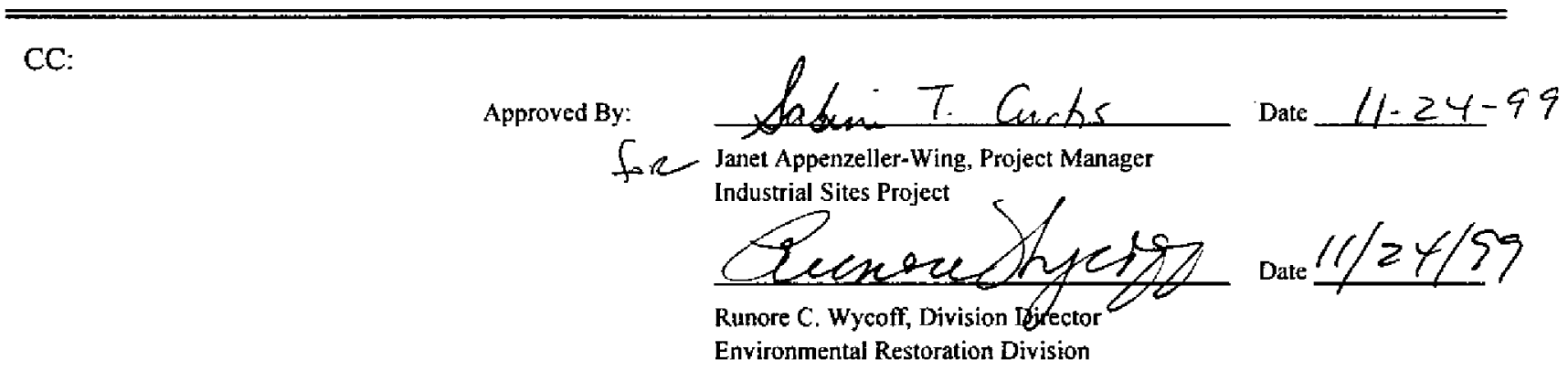




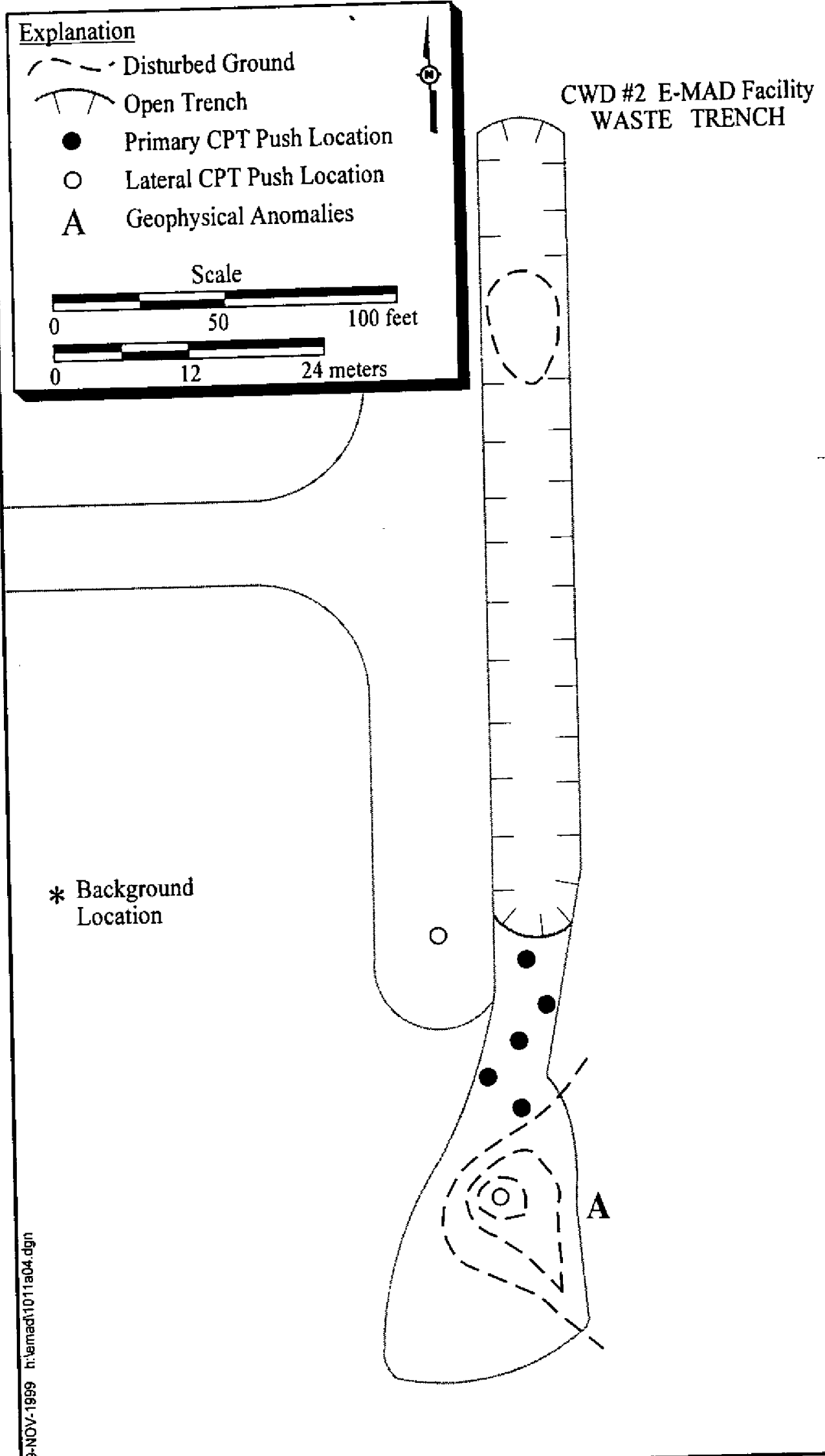

Revision: 1

Date: $11 \times \times / 99$

Page 30 of 47

Radioactive Leachfield

Figure 4-3

E-MAD Geophysical Anomaly and Approximate Borehole Locations 